\title{
A novel method to quantify local CpG methylation density by regional methylation elongation assay on microarray Dingdong Zhang ${ }^{\dagger 1,2}$, Yan Wang ${ }^{\dagger 1}$, Yunfei Bai ${ }^{1}$, Qinyu Ge ${ }^{1}$, Yingjuan Qiao1, Junfeng Luo ${ }^{1}$, Chao Jia ${ }^{1}$ and Zuhong Lu*1
}

Address: ${ }^{1}$ State Key Laboratory of Bioelectronics, Southeast University, Nanjing 210096, China and ${ }^{2}$ College of Animal Science and Technology, Jinling Institute of Technology, Nanjing 210038, China

Email: Dingdong Zhang - zdd_7597@seu.edu.cn; Yan Wang - wfyee@163.com; Yunfei Bai - whitecf@seu.edu.cn; Qinyu Ge - qgge2004@163.com; Yingjuan Qiao - gbbgbb@etang.com; Junfeng Luo - lbee1978_down@163.com; Chao Jia - jiachaonj@hotmail.com; Zuhong Lu* - zhlu@seu.edu.cn

* Corresponding author †Equal contributors

Published: 31 January 2008

BMC Genomics 2008, 9:59 doi:10.1 |86/147|-2164-9-59
Received: 8 May 2007

Accepted: 31 January 2008

This article is available from: http://www.biomedcentral.com/I47I-2/64/9/59

(c) 2008 Zhang et al; licensee BioMed Central Ltd.

This is an Open Access article distributed under the terms of the Creative Commons Attribution License (http://creativecommons.org/licenses/by/2.0), which permits unrestricted use, distribution, and reproduction in any medium, provided the original work is properly cited.

\begin{abstract}
Background: DNA methylation based techniques are important tools in both clinical diagnostics and therapeutics. But most of these methods only analyze a few CPG sites in a target region. Indeed, difference of site-specific methylation may also lead to a change of methylation density in many cases, and it has been found that the density of methylation is more important than methylation of single $C_{p} G$ site for gene silencing.
\end{abstract}

Results: We have developed a novel approach for quantitative analysis of $C_{p} G$ methylation density on the basis of microarray-based hybridization and incorporation of Cy5-dCTP into the Cy3 labeled target DNA by using Taq DNA Polymerase on microarray. The quantification is achieved by measuring $\mathrm{Cy} 5 / \mathrm{Cy} 3$ signal ratio which is proportional to methylation density. This methylationsensitive technique, termed RMEAM (regional methylation elongation assay on microarray), provides several advantages over existing methods used for methylation analysis. It can determine an exact methylation density of the given region, and has potential of high throughput. We demonstrate a use of this method in determining the methylation density of the promoter region of the tumor-related gene MLHI, TERT and MGMT in colorectal carcinoma patients.

Conclusion: This technique allows for quantitative analysis of regional methylation density, which is the representative of all allelic methylation patterns in the sample. The results show that this technique has the characteristics of simplicity, rapidness, specificity and high-throughput.

\section{Background}

In the human genome, GC-rich DNA sequences are found frequently within the promoter and first exon of $\sim 50 \%$ of all genes [1]. These sequences, also known as CpG islands, can be targets of DNA methylation. An epigenetic phenomenon is known to be associated with genomic imprinting and X-chromosome inactivation, and essential for normal mammalian development [2]. Both global hypomethylation and regional hypermethylation have been described in human tumor cell lines and a wide spectrum of cancers [3]. Global hypomethylation has been associated with instability of chromosomal or microsatellite, while regional hypermethylation of $\mathrm{CpG}$ islands within promoter region of tumor suppressor genes 
is associated with transcriptional inactivation and represents an important mechanism of gene silencing in the pathogenesis of neoplasia $[4,5]$. There is emerging evidence that each tumor may harbor multiple genes susceptible to promoter hypermethylation. Methylation profiles of multiple genes for each cancer type might have important prognostic implications for clinical monitoring, risk assessment, and even therapeutic considerations [6-8].

The present techniques commonly used for the methylation analysis are based on the bisulfite modification of the genomic DNA. Since sodium bisulfite treatment exclusively converts unmethylated cytosine to uracil under appropriate conditions [9], subsequent analysis to differentiate unconverted cytosine from converted uracil enables us to know the primary methylation status. It is the basis for methylation-specific PCR (MSP) [10], bisulfite DNA sequencing [11], enzymatic regional methylation assay (ERMA) [12], pyrosequencing [13], and mass spectrometry [14]. MSP is widely used to analyze promoter methylation, although only a limited number of CpG sites can be analyzed by this method. Bisulfite DNA sequencing provides precise methylation status over an amplified region, but it requires large-scale sequencing of multiple plasmid clones. The major advantage of the pyrosequencing method compared to MSP is that the data are actual sequences rather than fluorescence data from PCR-based amplification. But highly repetitive thymines and the limitation of $\sim 75$ bp extension length [15] can affect assay reproducibility and accuracy. Mass spectrometry permits the high-throughput identification of methylation sites and the semiquantitative measurement at single or multiple CpG positions, but this method needs high quality and a large amount of samples, and sometimes false positive results are inevitable. Even though ERMA can determine overall methylation level within a region containing a number of $\mathrm{CpG}$ sites, but it requires radioactive labeling of DNA samples and subsequent cumbersome purification steps of the radiolabeled products. Recently, several groups have shown that the methylation status can be achieved by $5 \mathrm{mC}$-antibodies or MBD-proteins [16-18]. However, the affinity and specificity would be further improved for methylation density detection.

Microarrays provide the powerful tools for mapping the epigenome and detecting patterns of DNA methylation in the genome level [19-24]. Methods Coupling CpG-recognizing restriction enzymes with microarray technique have been reported, such as differential methylation hybridization (DMH) $[19,23]$, methylation amplification DNA chip (MAD) [22], and microarray-based integrated analysis of methylation by isoschizomers (MIAMI) [21]. The above methods are only able to analyze methylation at the restriction sites of the enzymes, which are poten- tially biased by mutations or polymorphisms at the sites. Another microarray approach for methylation pattern analysis is methylation-specific oligonucleotide (MSO) microarray $[19,20]$. MSO uses bisulfite-treated DNA as template for non-discriminatory PCR amplification, followed by hybridization of the PCR products to glass slides with oligonucleotides that could discriminate between methylated and unmethylated cytosines at specific CpG positions. One of the great potentials of MSO is that multiple genes can be analyzed on the same array. A potential limitation of this method is that closely spaced CpGs may not be amenable to analyze if the gene in question is heterogeneously methylated. Recently, genomic tiling microarray has been used to profile DNA methylation patterns [24]. But this method can not obtain exact informations of methylation level within the given region of specific caner-related genes.

Here, we describe a novel technique for the quantification of CpG methylation density of a given DNA region, which combines microarray-based hybridization and enzymatic elongation on microarray. The quantification is achieved by measuring $\mathrm{Cy} 5 / \mathrm{Cy} 3$ signal ratio which is proportional to methylation density. In contrast to the other protocols, this method determines the methylation density of the entire amplified region, not only of a few CpG sites or those CpG dinucleotides that are covered by PCR primers/ probes. The results show that this technique allows for the quantitative analysis of regional methylation density with simplicity, rapidness, specificity and high-throughput.

\section{Results \\ Principle of the method}

Figure 1 outlines the RMEAM (regional methylation elongation assay on microarray) strategy for DNA methylation density analysis. Test DNA samples are bisulfite-modified, PCR amplified products which contain pools of DNA fragments with altered nucleotide sequences due to their differential methylation status. As shown, the unmethylated allele of a given DNA sequence is expected to have the unmethylated cytosine of the test $\mathrm{CpG}$ sites converted to thymine, whereas these $\mathrm{CpG}$ sequences remain unchanged in the methylated allele. The information on cytosine methylation can now be converted into sequence information. The region of interest is amplified with primers that are specific for bisulfite-modified DNA without $\mathrm{CpG}$ dinucleotides in the sequence, which ensures that the PCR amplification is independent of the original methylation status. Thus, the number of CpG dinucleotides remaining in the amplified region would reflect original methylation status. Subsequently, the forward primer was modified with $-\mathrm{NH}_{2}$ at $5^{\prime}$ end, and then fixed on the aldehyde coating glass as probe leaving 3 '-OH free. Target DNA is then hybridized to arrayed oligonucleotide probes which are specifically designed to match the 


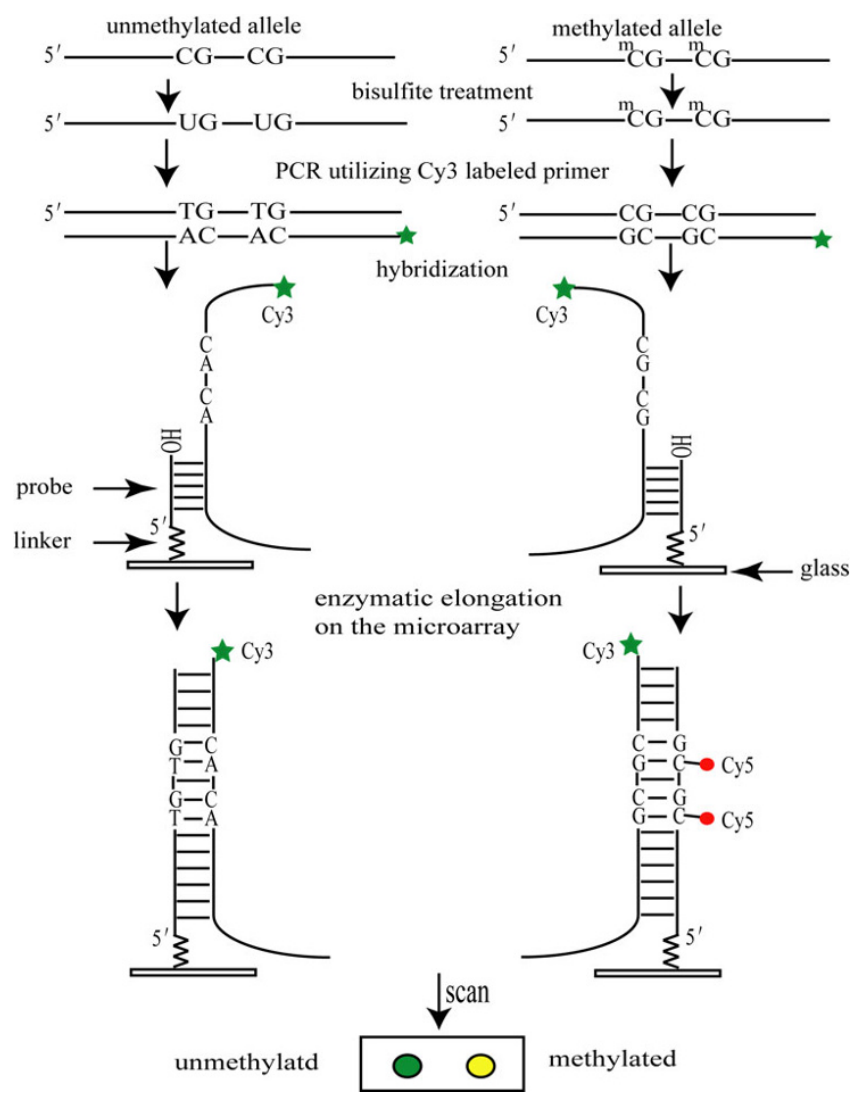

Figure I

Outline for the analysis of gene promoter methylation density.

reverse strands. For quantification of $\mathrm{CpG}$ dinucleotides, enzymatic elongation was carried out with dNTPs (dATP, dGTP, dTTP, dCTP, Cy5-dCTP), PCR buffer, $\mathrm{Mg}^{2+}$ and Taq enzyme on microarray. The incorporation of Cy5-dCTP into the DNA is proportional to the number of methylated $\mathrm{CpG}$ sites originally present in this DNA region. To minimize the background signal and solve the problem that a variable quantity of DNA has different fluorescence intensities in every reaction tube, we devised a smart way to accurately standardize between samples. For this step, we modified Cy3 at the 5'end of reverse primers and the Cy3 labeled reverse strands were hybridized to the oligonucleotide probes. Because the number of $\mathrm{Cy} 3$ is identical for every PCR product, the Cy3 signal can be used as an internal control to standardize the amount of DNA that is finally analyzed. The results are expressed as fluorescence intensity ratio (Cy5/Cy3). By use of the mixture of fullymethylated and non-methylated alleles as standards, the ratios can be converted into percentage values, and thus, the average methylation density of the amplified region is determined. However, considering standardization of Cy3 and Cy5 fluorescence intensity as well as quality control, we use a positive control (fully-methylated APC allele from clone) just like the housekeeping gene of cDNA microarray and a negative control which removes the influence of cross-hybridization. This positive control has definite number of $\mathrm{CPG}$ sites and merges the PCR products before the hybridization. Thus, the fluorescence intensity ratios (Cy5sam*Cy3pos)/(Cy5pos*Cy3sam) will be proportional to the methylation density in the original sequence (sam: sample; pos: positive control).

\section{Optimization of assay conditions for the MLHI, TERT and MGMT promoter region}

We determined the feasibility of this RMEAM strategy by assessing the methylation density of $\mathrm{CPG}$ islands located in the promoter regions of MLH1, TERT and MGMT (Fig. $2 \mathrm{~A})$, and it has been proved that the mathylation of MLH1, TERT and MGMT are associated with carcinogenesis of colorectal tumor. A group of forty-arrayed oligonucleotides (Five rows of probes which have eight replicated spots; See Fig. 2B and Fig. 3A) were designed to hybridize with the labeled PCR products. The number of CpG sites in positive control (APC), MLH1, TERT and MGMT were $16,23,27$ and 28 respectively (Fig. 2A). Fully-methylated

\begin{tabular}{|c|c|c|c|c|}
\hline & \multicolumn{4}{|c|}{$\begin{array}{l}\text { ggggttagggttaggtaggttgtgCGgttgggCGgggttttgtgtttattgCGgagtg } \\
\text { CGggtCGggaagCGgagagagaagtagttgtgtaattCGttggatgCGgattagg } \\
\text { gCGtttttattttCGtCGggagttCGtCGattggttgggtgtgggCGtaCGtgatC } \\
\text { Gatatgtggttgtattggtgtagtt }\end{array}$} \\
\hline & \multicolumn{4}{|c|}{$\begin{array}{l}\text { tttttaggagtgaaggaggttaCGggtaagtCGttttgaCGtagaCGtttattagggt } \\
\text { CGCGCGttCGtCGttCGttatatatCGttCGtagtattCGtgtttagtttCGtagtg } \\
\text { gCGtttgaCGtCGCGttCGCGggtagttaCGatgaggCGgCGatagattaggt } \\
\text { atagggttttat }\end{array}$} \\
\hline & \multicolumn{4}{|c|}{$\begin{array}{l}\text { gggttattttatagtttaggtCGattCGatttttttCGttggggtttcGttggCGttttgt } \\
\text { attttgggagCGCGagCGgCGCGCGggCGgggaagCGCGgtttagattttC } \\
\text { GggttCGttCGgagtagttgCGttgtCGgggttaggtCGggttttagtggattCG } \\
\text { CGggtatagaCGttaggatCGCGtttttaCGtggCGgagggattggggatt }\end{array}$} \\
\hline & \multicolumn{4}{|c|}{$\begin{array}{l}\text { ggatatgttgggatagttCGCGtttttagaaCGtttgCGtttC } \\
\text { ttCGCGgtgCGtatCGtttgCGatttggtgagtgtttgggtC } \\
\text { gagtgCGgagtttttttCGggaCGgtggtagtttCGagtgg } \\
\text { tttCGtCGtCGggtgtggggtCGtttgatttttatttatttCGg } \\
\text { GttttaagtgtttttaggtgttgtttagtttttttCGggtttggggtt }\end{array}$} \\
\hline \\
\hline & & & & $n$ \\
\hline sit & trol & 196 & 16 & $5^{\prime}-\mathrm{NH}_{2}$ \\
\hline gati & ntrol & ノ & ノ & 5'- $\mathrm{NH}_{2}-(\mathrm{T})_{10}$ - GGGGGAGATTTAATTTGG-3' \\
\hline & & 182 & 23 & TAGGAGTGAAGGAGG- \\
\hline & & 4 & 27 & $5{ }^{\prime}-\mathrm{NH}_{2}-(\mathrm{T})_{10}$-GGGTTATTTTATAGTTTAGG \\
\hline MGI & ne & 289 & 28 & $5 \cdot-\mathrm{NH}_{2}-(\mathrm{T})_{10^{-}}-$ \\
\hline \multicolumn{5}{|l|}{ gur } \\
\hline \multicolumn{5}{|r|}{$\begin{array}{l}\text { slated region } \\
\text { llele from } \\
\text { yed. The } \\
\text { green color) } \\
\text { vithout CpG } \\
\text { probes, the } \\
\text { are shown. }\end{array}$} \\
\hline
\end{tabular}



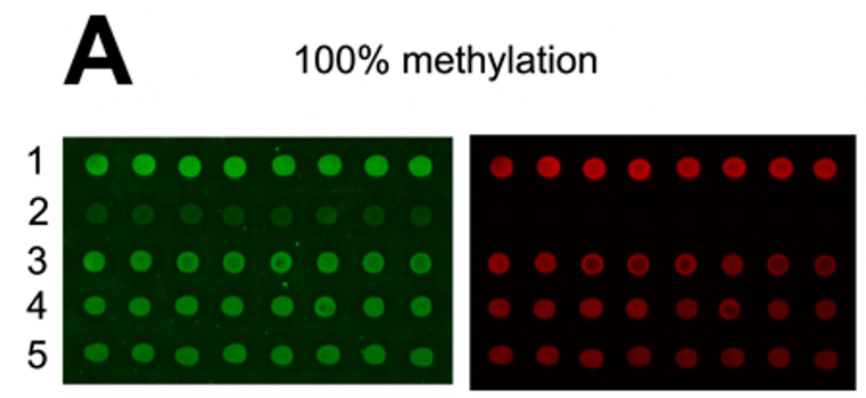

$75 \%$ methylation

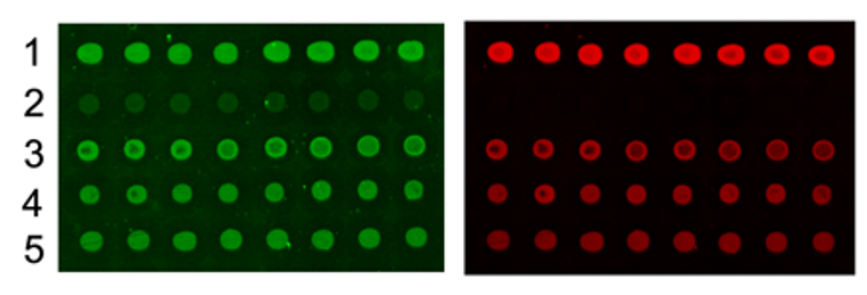

$50 \%$ methylation

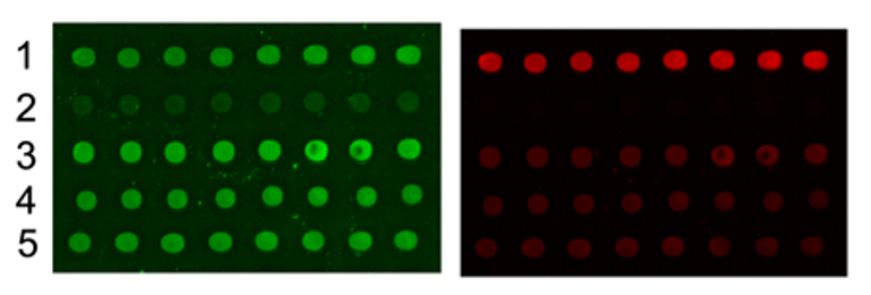

$25 \%$ methylation
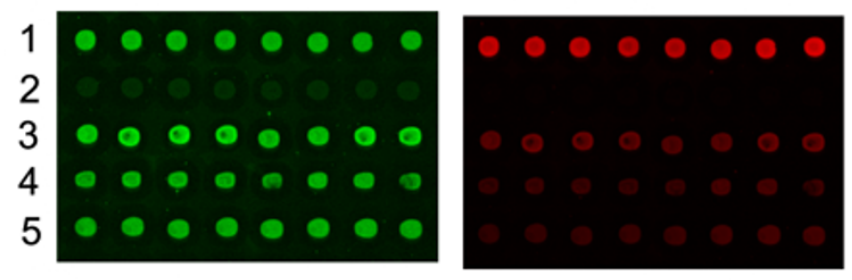

$0 \%$ methylation
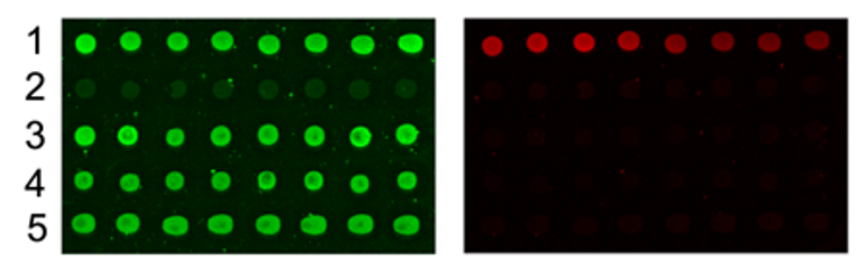
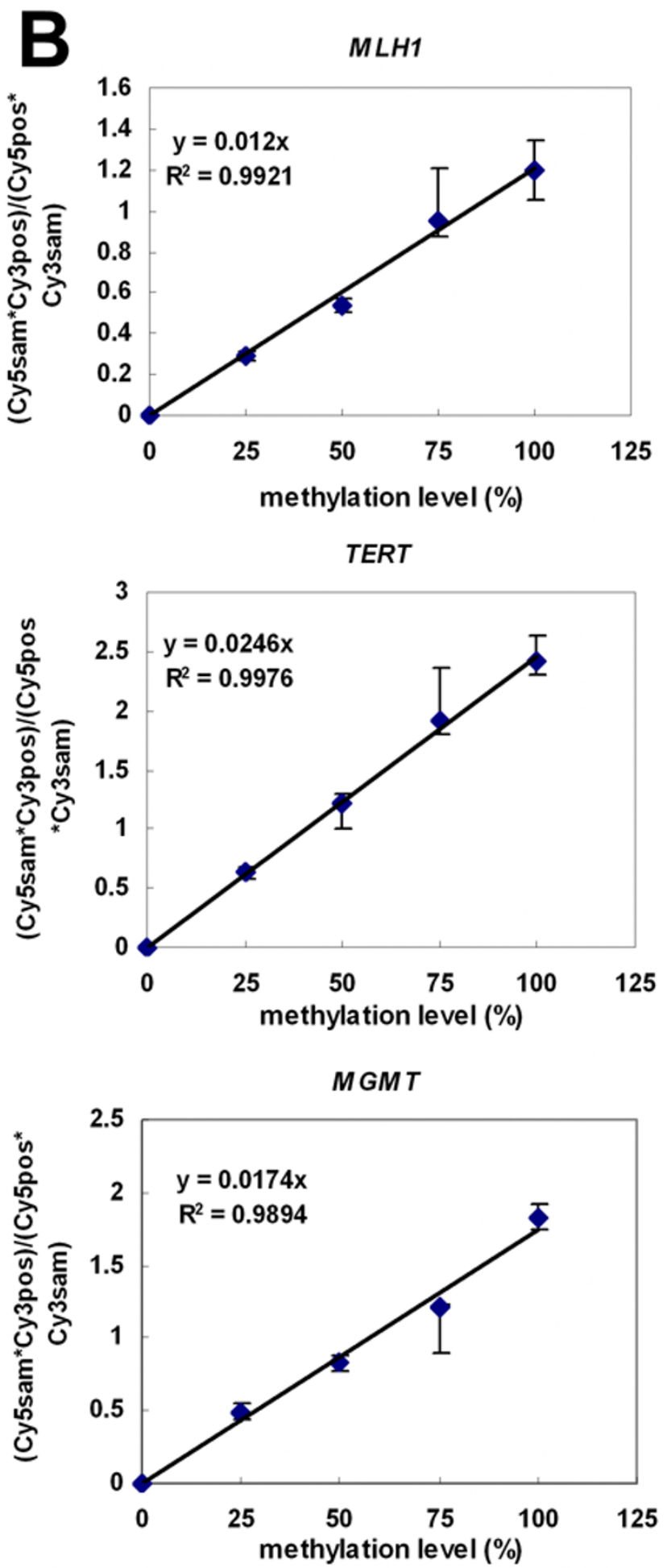

\section{Figure 3}

A: Fully methylated and unmethylated DNA were mixed (0\%, 25\%, 50\%, 75\%, 100\%) and hybridized to microarray. The Cy3 green and Cy5 red fluorescence signals of $M L H I$, TERT and MGMT promoter region are shown, reflecting the indicated percentage of methylation. From top to bottom, the five probes are positive control (I), negative (2), MLHI (3), TERT (4) and MGMT (5). B: Three calibration curves for measuring methylation densities in MLHI, TERT and MGMT promoter region. The intensity ratios ( $\mathrm{Y}$-axis) represent signal intensities of (Cy5sam*Cy3pos)/(Cy5pos*Cy3sam). 
and non-methylated DNA targets amplified from clones of these three genes were used to test the accuracy and reproducibility of the RMEAM method. A 182-bp fragment of the MLH1 promoter region, a 224-bp fragment of the TERT promoter region and a 289-bp fragment of the MGMT promoter region were amplified by triplex PCR using primers that were specific for bisulfite-converted DNAs (Fig. 2B). The fully-methylated alleles generated in this way had $100 \%$ unconverted cytosine in the test CpG sites, whereas the non-methylated alleles had all cytosine residues converted into thymine in the amplified DNA.

To evaluate the sensitivity and quantitative accuracy of our assay as well as determining any possible PCR bias [25], we then carried out mixing experiments using methylation positive clones and methylation negative clones. The mixtures were prepared prior to PCR in order to assess the possibility of bias during the PCR amplification [12]. The mixtures of Cy3-labeled fully-methylated allele and non-methylated allele with different proportion merged the Cy3-labeled positive control. And then a series of microarray hybridization were performed. After hybridization, elongation was carried out. Optimal elongation conditions on microarray were determined in order to allow elongation reactions to go to completion. Figure 3 shows that there is a linear correlation between the defined methylation density of the standard clone dilutions and the $\left(\mathrm{Cy} 5 \mathrm{sam}^{*} \mathrm{Cy} 3 \mathrm{pos}\right) /\left(\mathrm{Cy} 5 \mathrm{pos}^{*} \mathrm{Cy} 3 \mathrm{sam}\right)$ signal ratios. By including mixtures of clones as standards (fully-methylated only, $75 \%$ fully-methylated $/ 25 \%$ nonmethylated, $50 \%$ fully-methylated $/ 50 \%$ non-methylated, $25 \%$ fully-methylated $/ 75 \%$ non-methylated and nonmethylated only, corresponding to $100 \%, 75 \%, 50 \%$, $25 \%$ and $0 \%$ methylation density) in every assay [12], it is possible to create a standard curve in order to control for differential specific activity and incorporation efficiency of the Cy5-dCTP. This standard curve can then be used to calculate the methylation density of unknown samples from the ratios (Cy5sam*Cy3pos)/(Cy5pos*Cy3sam). All standards and unknown samples were analyzed with eight replications.

\section{Verification of RMEAM findings by bisulfite sequencing} In order to validate the accuracy of the RMEAM approach, we analyzed the MLH1, TERT and MGMT promoter methylation density in 18 colorectal carcinoma patients. Figure 4 showed that this assay could detect precisely the methylation density in every patient sample. In these samples, MLH1 promoter had $0 \%-5.21 \%$ methylation density (mean, 0.78\%); TERT promoter had 1.18\%-12.59\% methylation density (mean, $4.48 \%$ ) and MGMT promoter had 1.55\%-30.84\% methylation density (mean 14.44\%). The region of MLH1 promoter in this assay was selected according to Maekawa et al [26]. This region is a little farther than the region relative to the transcriptional start site

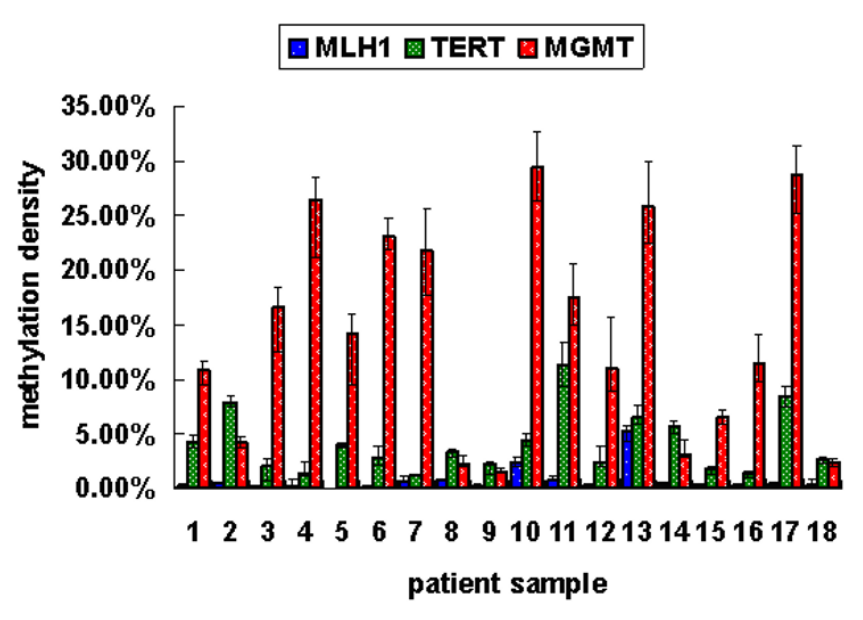

Figure 4

MLHI, TERT and MGMT promoter methylation densities of tumor samples from 18 patients with colorectal tumor.

of MLH1 described by Deng et al. [27]. Consequently the methylation level of this region is relative low.

When we compared our RMEAM results with succedent bisulfite sequencing data, a high concordance between both methods was found. Figure 5 showed the correlations between the results obtained by RMEAM with the data from bisulfite sequencing in MLH1, TERT and MGMT promoter regions of 18 colorectal tumor patients.

\section{Discussions}

We developed a novel approach for quantitative analysis of CpG methylation density on the basis of microarraybased hybridization and incorporation of Cy5-dCTP into the Cy3 labeled target DNAs by using Taq DNA Polymerase on microarray. This method provides several advantages over existing methods for quantitative methylation analysis. Firstly, it has potential for high-throughput analysis of DNA methylation profiles. CpG island hypermethylation has been reported to be linked to the silencing of many cancer-related genes. A DNA microarray can be designed and generated to contain a large amount of oligonucleotide probes capturing specifically target genes. Cancer-related genes can be parallelly amplified from investigated samples in a 96-well format or with multiple PCR, which can generate multiple target genes for hybridization and detection. Secondly, RMEAM can determine the methylation density of all $\mathrm{CpG}$ dinucleotides within the entire amplified region other than individual CpG sites. In the case of the MGMT promoter region, the detected methylation density includes the methylation status of $28 \mathrm{CpG}$ dinucleotides. RMEAM produced a linear response when used for quantitative methylation analysis in mixing experiments by use of DNA from fullymethylated and non-methylated clones with a defined 


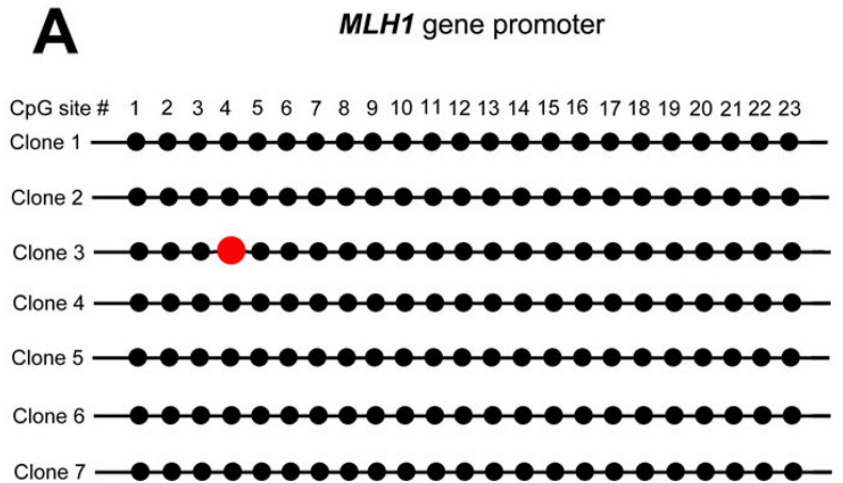

TERT gene promoter

Cpg site \# $1125 \quad 3 \quad 4 \quad 5 \quad 6 \quad 7 \quad 8 \quad 9 \quad 101112131415161718192021222324252627$ Clone 1 Clone 2 Clone 3 Clone 4 Clone 5 Clone 6 Clone 7

MGMT gene promoter

CpG site \# $1122 \quad 3 \quad 4 \quad 5 \quad 6 \quad 7 \quad 8 \quad 9 \quad 10111213141516171819202122232425262728$ Clone 1 - -0 Clone 2 Clone 3 Clone 4 - Clone $5 \longrightarrow-0$ Clone 6 Clone 7 -
B
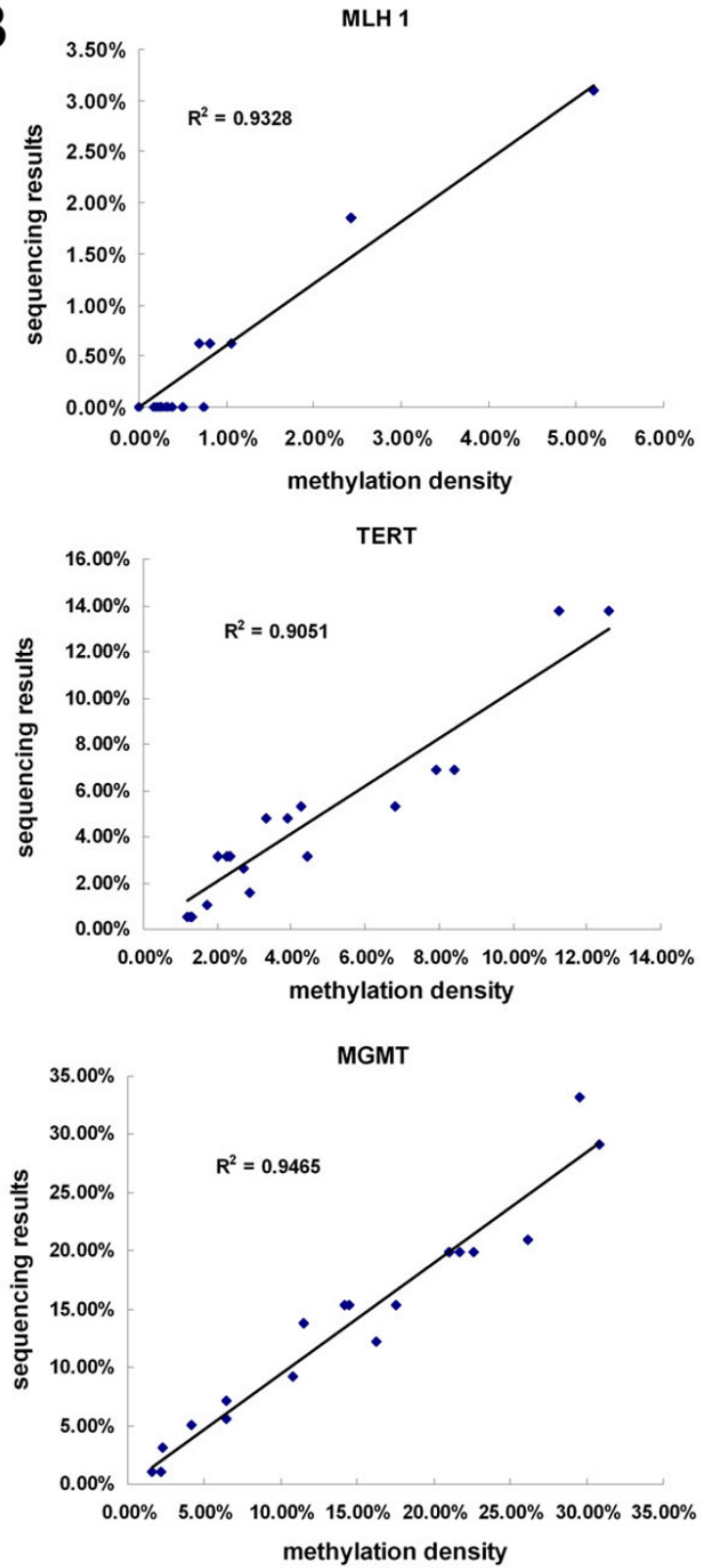

Figure 5

A: Representative sequencing data of patient No. 17 was shown. Red circle indicates the methylated CpG site. 7 clones or less per gene in each patient sample were sequenced. B: Correlations between bisulfite sequencing results and methylation density data of the MLHI, TERT and MGMT promoter region determined by our new assay in 18 patients with colorectal carcinoma.

methylation status. The third feature of RMEAM is its simplicity and precision. Unlike ERMA method [12], RMEAM doesn't require radioactive labeling of DNA samples and subsequent cumbersome purification steps of the radiolabeled products in tubes. Hybridization, elongation and washing on microarray can be quickly and easily achieved within 4 hours. The use of an internal control (Cy3) allows for correction of potential substrate loss and for normalization of the results to the DNA amount that is finally analyzed by microarray scaner. The negative control in Figure 3 can remove the influence of cross-hybridization. For example, the net Cy3 intensities of row 1, 3, 4 and 5 of Figure $3 \mathrm{~A}$ can be derived by subtraction of the row 2 negative control background. In row 2, the non-specific hybridization can't bring incorporation of Cy5-dCTP into the DNA due to the specificity of Taq DNA Polymer- 
ase. Dual-color fluorescence can be standardized by positive control, just like house-keeping gene in cDNA microarray. The accuracy of our new technique is shown by the high concordance with bisulfite sequencing data. However, in this study, only 7 clones or less per gene in each patient sample were sequenced, which might account for the slight discrepancies in methylation percentages (Figure 5). As cloning and final sequencing of a small number of alleles does not necessarily give representative data for the initial sample, the approach used in our current assay can provide more informations regarding the overall methylation density of the region from the sum of all alleles. Furthermore, RMEAM approach is less costly and labor intensive than the extensive bisulfite sequencing analysis needed for precise quantitation.

One possible limitation of our method is that it is not suitable for a detailed characterization of the pattern of DNA or the determination of methylation status of individual $\mathrm{CpG}$ sites. However, since difference of site-specific methylation may also lead to a change of methylation density in many tumor-related genes, It has been indicated that the methylation density of promoter $\mathrm{CpG}$ islands is more important than methylation occurred at a specific single CpG site for gene silencing [28-32]. Nevertheless, it has been very difficult to measure the level of methylation in a target area containing multiple CpG sites. Results with our new assay might be more biologically relevant, especially in patient samples with heterogeneous methylation patterns. Furthermore, it was suggested in an in vitro model that de novo CpG island methylation is not a single event, but rather a progressive process, and appears to be region specific [33]. Therefore, it is reasonable to apply a method that accurately determines the methylation density of a $\mathrm{CpG}$ island region in order to investigate the dynamics of methylation changes in human malignancies.

One of the potential applications of RMEAM approach is to examine the changes in methylation patterns following treatment with demethylating drugs [34]. Galm et al. [12] had demonstrated the application of ERMA technique for the quantitative analysis of methylaiton density, in which KG1a cells were treated in vitro with the increasing 5 'aza2'-deoxycytidine (DAC) dose within a given time course. The findings in that paper indicated that the changes of methylation density could help to optimize the dosage of demethylating drugs for clinical use by determining the extent of demethylation at a dose range with little cytotoxic side effects. Large-scale screenings of tumor-related genes under various conditions are needed to elucidate the functional role of DNA methylation and to screen for new antineoplastic drugs operative on that mechanism. Our new method could help elucidate the consequences of treating patients with such drugs and eventually help clarify their therapeutic value in future antineoplastic therapy regimens. Recent evidence has indicated that increased density of methylation within a susceptible CpG island is associated with more advanced stages of tumors. Our RMEAM method coupled with quantitative real-time PCR approaches to detect gene expression levels will contribute to more accurately assess the dynamics of methylation-mediated transcriptional silencing of tumorrelated genes in carcinogenesis. Such assays would preferably be genome-wide to monitor both desired and undesired effects on methylation and gene expression.

\section{Conclusion}

We described a novel approach for quantitative analysis of CPG methylation density on the basis of microarraybased hybridization and incorporation of Cy5-dCTP into the Cy3 labeled target DNA by using Taq DNA Polymerase on microarray. Our results showed that this RMEAM technique allows for the quantitative analysis of regional methylation density with simplicity, rapidness, specificity and high-throughput.

\section{Methods}

\section{Patients and DNA extraction}

Informed written consent was obtained from all patients and donors, and tissue collection was approved by each Institutional Review Board. The samples of primary tumor tissues were collected from colorectal carcinoma patients $(n=18)$ during surgery at Gulou Hospital and Zhongda Hospital (Nanjing, China). All tissue samples were freshfrozen and stored at $-80^{\circ} \mathrm{C}$ until further processing. Genomic DNA was extracted from tissues by digesting with proteinase $\mathrm{K}(0.5 \mathrm{mg} / \mathrm{ml})$ in $10 \mathrm{mM}$ TE $(\mathrm{pH} 8.0)$ buffer and $0.5 \%$ SDS at $48^{\circ} \mathrm{C}$ overnight, followed by a standard phenol/chloroform (1:1) extraction and precipitated with ethanol in a standard fashion.

\section{Bisulfite modification of genomic DNA}

Bisulfite treatment was carried out following the modified [35] procedure of Frommer et al. [11]. Briefly, $5 \mu \mathrm{g}$ of genomic DNA were digested with EcoRI (New England Biolabs) and denatured with $0.3 \mathrm{M} \mathrm{NaOH}$ for $15 \mathrm{~min}$ at $37^{\circ} \mathrm{C}$. A freshly prepared solution of sodium bisulfite (2.5 $\mathrm{M}, \mathrm{pH}$ 5.0) and hydroquinone (100 $\mathrm{mM})$ was added to the denatured DNA, and the mixture was incubated at $55^{\circ} \mathrm{C}$ for $5 \mathrm{~h}$. After desalting (Wizard Clean Up System; Promega), the DNA was desulphonated with $0.3 \mathrm{M} \mathrm{NaOH}$ for $15 \mathrm{~min}$ at $37^{\circ} \mathrm{C}$. The solution was neutralized with 75 $\mu \mathrm{l}$ of $5 \mathrm{M}$ ammonium acetate ( $\mathrm{pH} 7.0$ ), and the DNA was ethanol precipitated and resuspended in Tris-EDTA $(\mathrm{pH}$ 7.5).

\section{Preparation of the positive and negative clones}

Placental DNA treated in vitro with SssI methyltransferase (New England Biolabs) was used as fully-methylated alle- 
les for APC, MLH1, TERT and MGMT gene. Meanwhile, DNA from normal lymphocytes was used as unmethylated alleles for MLH1, TERT and MGMT gene. Sodium bisulfite modification of the unmethylated DNA and M. SssI-treated DNA were then performed. The targeted CpG islands (see Fig. 2) were amplified from bisulfite-treated genomic DNA by triplex PCR using the following primer pairs [26,36,37]. The primers used were MLH1-Forward, 5'-TTTTTTAGGAGTGAAGGAGG-3'; MLH1-Reverse, 5'ATAAAACCCTATACCTAATCTATC-3'; MGMT-Forword, 5'-GGATATGTTGGGATAGTT-3'; MGMT-Reverse, 5'CCAAAAACCCCAAACCC-3'; TERT-Forward, 5'-GGGTTATTTTATAGTTTAGGT-3'; TERT-Reverse, 5'-AATCCCCAATCCCTC-3'. These primers are specific for bisulfite-modified DNA without CpG dinucleotides. The PCRs were performed in $25-\mu$ l reactions containing PCR buffer with $1.8 \mathrm{mM} \mathrm{MgCl}_{2}$, 5 pmol primer, 1.25 units Hot-start DNA polymerase (TaKaRa), and $1 \mu$ l bisulfitemodified DNA (equivalent to 50 ng genomic DNA). After an initial preheating step of $5 \mathrm{~min}$ at $95^{\circ} \mathrm{C}$, PCR was performed 40 cycles of $95^{\circ} \mathrm{C}$ for $30 \mathrm{~s}, 54^{\circ} \mathrm{C}$ for $30 \mathrm{~s}$, and $72^{\circ} \mathrm{C}$ for $30 \mathrm{~s}$, with a final extension at $72^{\circ} \mathrm{C}$ for $7 \mathrm{~min}$. APC fully-methylated allele was used as positive control which was amplified by forward primer 5'-GGGGTTAGGGTTAGGTAGG-3' and reverse primer 5'-AACTACACCAATACAACCACATA-3' [36]. All PCR products were gel purified and cloned into the pMD18-T vector according to the manufacturer's instructions (TaKaRa) and sequenced using the ABI sequencing system. Quantitation of the PCR product was performed with a UV spectrometer; $1 \mathrm{OD}_{260}$ unit was calculated as $50 \mathrm{ng} / \mu \mathrm{L}$.

\section{Fabrication and hybridization of microarray}

Five probes (18-20 nucleotides in length, Fig. 2) were synthesized with an amino-linked $\mathrm{C} 6\left[\mathrm{NH}_{2}\left(\mathrm{CH}_{2}\right)_{6}\right]$ linker attached to its 5 'end. Additional 10 nucleotides $\mathrm{T}$ were used to reduce the space influence. Each oligonucleotide was printed on the aldehyde-coated glass slides using a PixSys5500 microarrayer (Cartesian Technology Inc). After printed, the glass slides were incubated in a humid chamber at room temperature overnight, and then at $37^{\circ} \mathrm{C}$ for $2 \mathrm{~h}$. The slides were washed thoroughly in $1 \%$ SDS solution to remove unbound oligonucleotides. After further treatment with a $\mathrm{NaBH}_{4}$ solution for $20 \mathrm{~min}$, the slides were ready for hybridization. For target DNA labeling, PCR products of bisulfite-treated DNA were labeled at the 5'end of reverse primer with Cy3. The labeled products were resuspended in hybridization solution (1:3 dilution $\mathrm{v} / \mathrm{v}$ ). Then the mixture was denatured at $95^{\circ} \mathrm{C}$ for 5 min, immediately cooled on ice for $10 \mathrm{~min}$ and subsequently applied to the DNA microarray slides. Microarray hybridization was conducted in a moist hybridization chamber under a cover slip at $42^{\circ} \mathrm{C}$ for $3 \mathrm{~h}$ recommended by Schumacher et al [38].

\section{Elongation on microarray}

After hybridization, the slide was rinsed and washed at room temperature with $2 \times$ SSC- $0.1 \%$ SDS for $10 \mathrm{~min}, 0.1$ $\times$ SSC- $0.1 \%$ SDS for $5 \mathrm{~min}$, water for $5 \mathrm{~min}$, and then dried by flowing nitrogen. Then $15 \mu \mathrm{L}$ elongation system was applied to the hybridization region with a cover slip. The elongation system contained $1 \times$ PCR buffer, $2.5 \mathrm{mM}$ $\mathrm{Mg}^{2+}$, dNTPs ( $20 \mu \mathrm{M}$ dGTP, $20 \mu \mathrm{M}$ dATP, $20 \mu \mathrm{M}$ dTTP, 0.2 $\mu \mathrm{M}$ dCTP, $0.2 \mu \mathrm{M}$ Cy5-dCTP), and 1.5 IU Taq DNA Polymerase $(\mathrm{TaKaRa})$. The incubation procedure was $42^{\circ} \mathrm{C} 10 \mathrm{~min}, 55^{\circ} \mathrm{C} 5 \mathrm{~min}$, and $72^{\circ} \mathrm{C} 3 \mathrm{~min}$. Subsequently, the slide was washed with $2 \times$ SSC-0.5\% SDS and dried, and it was ready to be scanned.

\section{Image scanning and data processing}

These microarray slides were scanned with ScanArray Lite microarray analysis systems (A Packard BioScience Company, USA). The fluorescence images were analyzed with GenePix Pro3.0 software. Each spot was defined by the positioning of a grid of circles over the array image. For each fluorescent image, the average pixel intensity within each circle was determined and a local background using mean pixel intensity was computed for each spot. Net signal was determined by subtraction of this local background from the mean average intensity for each spot and the nospecific influence of cross-hybridization from negative control. Signal intensities of individual spots were obtained and exported to Excel spreadsheets for further analysis. The intensity ratio of $\mathrm{Cy} 5 / \mathrm{Cy} 3$ for each probe set was then obtained.

\section{Authors' contributions}

$\mathrm{DZ}$ and ZL designed the study and wrote the manuscript, YW performed the fabrication of microarray and microarray hybridization, $\mathrm{YB}$ and QG provided the positive and negative clones of APC, MGMT, MLH1, TERT genes, YQ performed bisulfite modification and PCR, JL provided genomic DNA of colorectal cancer tissue samples, and CJ performed data analysis. All authors read and approved the final manuscript.

\section{Acknowledgements}

This work was funded by the National Natural Science Foundation of China (Project 60121101, 60701008), the Hi-Tech Research and Development Program of China (Project 2006AA020702), and the National Basic Research and Development Program (973 Program) of China (Grant No. 2006CB705602-9).

\section{References}

I. Antequera F, Bird A: Number of $\mathrm{CpG}$ islands and genes in human and mouse. Proceedings of the National Academy of Sciences of the United States of America 1993, 90(24): I 1995-I 1999.

2. Rountree MR, Bachman KE, Herman JG, Baylin SB: DNA methylation, chromatin inheritance, and cancer. Oncogene 200I, 20(24):3।56-3165.

3. Jones PA, Takai D: The role of DNA methylation in mammalian epigenetics. Science 200I, 293(5532): I068-1070.

4. Baylin SB, Herman JG: DNA hypermethylation in tumorigenesis: epigenetics joins genetics. Trends Genet 2000, I6(4):168-174. 
5. Jones PA, Laird PW: Cancer epigenetics comes of age. Nature genetics 1999, 21 (2): 163-167.

6. Brock MV, Gou M, Akiyama Y, Muller A, Wu TT, Montgomery E, Deasel M, Germonpre P, Rubinson L, Heitmiller RF, Yang SC, Forastiere AA, Baylin SB, Herman JG: Prognostic importance of promoter hypermethylation of multiple genes in esophageal adenocarcinoma. Clin Cancer Res 2003, 9(8):2912-2919.

7. Cheng YW, Shawber C, Notterman D, Paty P, Barany F: Multiplexed profiling of candidate genes for $\mathrm{CpG}$ island methylation status using a flexible PCR/LDR/Universal Array assay. Genome research 2006, 16(2):282-289.

8. Muller HM, Widschwendter A, Fiegl H, Goebel G, Wiedemair A, Muller-Holzner E, Marth C, Widschwendter M: A DNA methylation pattern similar to normal tissue is associated with better prognosis in human cervical cancer. Cancer letters 2004, 209(2):23I-236

9. Hayatsu H, Wataya $\mathrm{Y}, \mathrm{Kai} \mathrm{K}$, lida S: Reaction of sodium bisulfite with uracil, cytosine, and their derivatives. Biochemistry 1970 9( I 4):2858-2865.

10. Herman JG, Graff JR, Myohanen S, Nelkin BD, Baylin SB: Methylation-specific PCR: a novel PCR assay for methylation status of CpG islands. Proceedings of the National Academy of Sciences of the United States of America 1996, 93( I 8):982I-9826.

II. Frommer M, McDonald LE, Millar DS, Collis CM, Watt F, Grigg GW, Molloy PL, Paul CL: A genomic sequencing protocol that yields a positive display of 5-methylcytosine residues in individual DNA strands. Proceedings of the National Academy of Sciences of the United States of America 1992, 89(5): | 827-I83|

12. Galm O, Rountree MR, Bachman KE, Jair KW, Baylin SB, Herman JG Enzymatic regional methylation assay: a novel method to quantify regional CpG methylation density. Genome research 2002, I 2(I): $153-157$

13. Shames DS, Minna JD, Gazdar AF: Methods for detecting DNA methylation in tumors: from bench to bedside. Cancer letters 2007, 25 I(2): 187-198.

14. Ehrich M, Nelson MR, Stanssens $P$, Zabeau M, Liloglou T, Xinarianos G, Cantor CR, Field JK, van den Boom D: Quantitative highthroughput analysis of DNA methylation patterns by basespecific cleavage and mass spectrometry. Proceedings of the National Academy of Sciences of the United States of America 2005 , 102(44): I $5785-15790$.

15. Dupont JM, Tost J, Jammes H, Gut IG: De novo quantitative bisulfite sequencing using the pyrosequencing technology. Analytical biochemistry 2004, 333(I): 1 I9-127.

16. Fraga MF, Ballestar E, Montoya G, Taysavang P, Wade PA, Esteller M The affinity of different MBD proteins for a specific methylated locus depends on their intrinsic binding properties. Nucleic acids research 2003, 3 I(6): I765-I774.

17. Jorgensen HF, Adie K, Chaubert P, Bird AP: Engineering a highaffinity methyl-CpG-binding protein. Nucleic acids research 2006 34(13):e96

18. Roloff TC, Ropers HH, Nuber UA: Comparative study of methylCpG-binding domain proteins. BMC genomics 2003, 4(I): I.

19. Adorjan P, Distler J, Lipscher E, Model F, Muller J, Pelet C, Braun A, Florl AR, Gutig D, Grabs G, Howe A, Kursar M, Lesche R, Leu E, Lewin A, Maier S, Muller V, Otto T, Scholz C, Schulz WA, Seifert HH, Schwope I, Ziebarth H, Berlin K, Piepenbrock C, Olek A: Tumour class prediction and discovery by microarray-based DNA methylation analysis. Nucleic acids research 2002, 30(5):e2I.

20. Gitan RS, Shi H, Chen CM, Yan PS, Huang TH: Methylation-specific oligonucleotide microarray: a new potential for highthroughput methylation analysis. Genome research 2002, I 2(I): I58-164.

21. Hatada I, Fukasawa M, Kimura M, Morita S, Yamada K, Yoshikawa T, Yamanaka S, Endo C, Sakurada A, Sato M, Kondo T, Horii A, Ushijima $\mathrm{T}$, Sasaki H: Genome-wide profiling of promoter methylation in human. Oncogene 2006, 25(2I):3059-3064.

22. Hatada I, Kato A, Morita S, Obata Y, Nagaoka K, Sakurada A, Sato M, Horii A, Tsujimoto A, Matsubara K: A microarray-based method for detecting methylated loci. Journal of human genetics 2002 47(8):448-45I.

23. Huang TH, Perry MR, Laux DE: Methylation profiling of CpG islands in human breast cancer cells. Human molecular genetics 1999, 8(3):459-470.
24. Lippman Z, Gendrel AV, Colot V, Martienssen R: Profiling DNA methylation patterns using genomic tiling microarrays. Nature methods 2005, 2(3):219-224.

25. Warnecke PM, Stirzaker C, Melki JR, Millar DS, Paul CL, Clark SJ: Detection and measurement of PCR bias in quantitative methylation analysis of bisulphite-treated DNA. Nucleic acids research 1997, 25(2I):4422-4426.

26. Maekawa M, Sugano K, Kashiwabara H, Ushiama M, Fujita S, Yoshimori M, Kakizoe T: DNA methylation analysis using bisulfite treatment and PCR-single-strand conformation polymorphism in colorectal cancer showing microsatellite instability. Biochemical and biophysical research communications 1999, 262(3):67I-676.

27. Deng G, Chen A, Hong J, Chae HS, Kim YS: Methylation of CpG in a small region of the $\mathrm{hMLHI}$ promoter invariably correlates with the absence of gene expression. Cancer research 1999, 59(9):2029-2033

28. Cameron EE, Baylin SB, Herman JG: pI5(INK4B) CpG island methylation in primary acute leukemia is heterogeneous and suggests density as a critical factor for transcriptional silencing. Blood 1999, 94(7):2445-245 I.

29. Dodge JE, List AF, Futscher BW: Selective variegated methylation of the p/5 CpG island in acute myeloid leukemia. International journal of cancer 1998, 78(5):56I-567.

30. Hsieh CL: Dependence of transcriptional repression on CpG methylation density. Molecular and cellular biology 1994, I 4(8):5487-5494

31. Nagasaka T, Sharp GB, Notohara K, Kambara T, Sasamoto H, Isozaki $\mathrm{H}$, MacPhee DG, Jass JR, Tanaka N, Matsubara N: Hypermethylation of 0-6-methylguanine-DNA methyltransferase promoter may predict nonrecurrence after chemotherapy in colorectal cancer cases. Clinical Cancer Research 2003, 9(14):5306-53।2

32. Yan PS, Shi H, Rahmatpanah F, Hsiau TH, Hsiau AH, Leu YW, Liu JC, Huang TH: Differential distribution of DNA methylation within the RASSFIA CpG island in breast cancer. Cancer research 2003, 63(19):6178-6186.

33. Wong DJ, Foster SA, Galloway DA, Reid BJ: Progressive regionspecific de novo methylation of the pl6 CpG island in primary human mammary epithelial cell strains during escape from M(0) growth arrest. Molecular and cellular biology 1999 , 19(8):5642-565।.

34. Santini V, Kantarjian HM, Issa JP: Changes in DNA methylation in neoplasia: pathophysiology and therapeutic implications. Annals of internal medicine 200I, 134(7):573-586.

35. Raizis AM, Schmitt F, Jost JP: A bisulfite method of 5-methylcytosine mapping that minimizes template degradation. Analytical biochemistry 1995, 226(I): 16I-166.

36. Clement $G$, Benhattar J: A methylation sensitive dot blot assay (MS-DBA) for the quantitative analysis of DNA methylation in clinical samples. Journal of clinical pathology 2005, 58(2): I55-I58.

37. Palmisano WA, Divine KK, Saccomanno G, Gilliland FD, Baylin SB, Herman JG, Belinsky SA: Predicting lung cancer by detecting aberrant promoter methylation in sputum. Cancer research 2000, 60(2I):5954-5958.

38. Schumacher A, Kapranov P, Kaminsky Z, Flanagan J, Assadzadeh A Yau P, Virtanen C, Winegarden N, Cheng J, Gingeras T, Petronis A: Microarray-based DNA methylation profiling: technology and applications. Nucleic acids research 2006, 34(2):528-542. 